\title{
Comparison of Two Markov Models for a 30-Year Simulation of the Natural History of Intracranial Aneurysms
}

\author{
Suraj Patel, Aichi Chien \\ Department of Radiological Sciences, David Geffen School of Medicine at UCLA, Los Angeles, USA \\ Email: aichi@ucla.edu
}

Received 20 April 2014; revised 18 May 2014; accepted 5 June 2014

Copyright (C) 2014 by authors and Scientific Research Publishing Inc.

This work is licensed under the Creative Commons Attribution International License (CC BY).

http://creativecommons.org/licenses/by/4.0/

(c) (i) Open Access

\section{Abstract}

Objective: There are several Markov models which simulate long-term aneurysm growth and rupture. By comparing multiple models, we cannot only find a way to accurately simulate the growth and rupture behavior of untreated aneurysms in our database, but also find the best model to simulate aneurysm behavior for other studies. This will let us identify which aneurysms require invasive treatment. Methods: We analyzed 290 aneurysms in 29 males and 177 females. The mean diameter was $4.5 \pm 3.45 \mathrm{~mm}$, and the mean age was $61 \pm 13.22$ years. We tested Markov Model I and Markov Model II to simulate growth and rupture over 30 years, and growth and rupture were functions of aneurysm volume. At five-year intervals, we calculated the odds ratio and used the One-Way ANOVA and Independent T-Test to test the effects of aneurysm diameter and growth on the rupture rate. Results: After 30 years, the mean aneurysm sizes were $9.18 \pm 2.37 \mathrm{~mm}$ and $7.80 \pm$ $6.44 \mathrm{~mm}$ for Markov Models I and II, respectively. The mean rupture rate was $13.93 \% \pm 12.89 \%$ for Markov Model I and $\mathbf{1 4 . 1 5 \%} \pm \mathbf{2 1 . 9 6 \%}$ for Markov Model II. There was a significantly higher rupture rate and significant odds ratio for larger aneurysms and "Significant Growth" aneurysms at most five-year intervals. Conclusion: Aneurysms larger than $9.5 \mathrm{~mm}$ need immediate surgical treatment. For aneurysms between $3.5-9.5 \mathrm{~mm}$, early intervention is recommended if the growth rate exceeds $0.36 \mathrm{~mm} /$ year. Markov Model I is the optimal model for our database due to the unrealistically large aneurysms produced by Markov Model II.

\section{Keywords}

Computed Tomography Angiography, Growth, Longitudinal Study, Rupture, Treatment 


\section{Introduction}

Intracranial aneurysms have a notable prevalence in the general population, where $3 \%-5 \%$ of individuals are affected. If left untreated, these aneurysms can rupture, leading to the life-threatening subarachnoid hemorrhage (SAH) [1]-[9]. The current mortality rate for SAH is estimated to be $40 \%$, and an additional $20 \%$ of SAH cases lead to significant brain damage and permanent disability [1] [2] [4]-[6] [8] [9]. Because aneurysm rupture can be very debilitating, it is very important that we understand the risks of rupture as well as how unruptured aneurysms will behave over an extended period of time [9]-[12].

However, it is challenging to observe the natural history of these aneurysms in the clinical population [5] [13] [14]. First, many high-risk aneurysms are treated immediately rather than followed for a long time. Because neurosurgeons are obligated to treat any aneurysms which are likely to rupture, we may not see what would have eventually happened to those aneurysms had they not been treated [7]. Second, it is impractical to follow a patient population for a long time because it is difficult to keep in contact with $100 \%$ of the patients. Additionally, some patients may die of other unrelated health problems. Thus, we would not see what eventually happens to all of the aneurysms in that population [5] [14].

Because it is difficult to observe the natural history of aneurysms in patients, it is more practical to use a mathematical model to observe what would happen to the aneurysms if left untreated [9] [15] [16]. The studies by Yoshimoto and Chang both use a mathematical Markov chain model to predict the yearly growth rate and yearly rupture rate (YRR) of the aneurysms [15] [16]. The purpose of a Markov model is to simulate the behavior of an aneurysm to see the patterns of growth and rupture over a long period of time.

There are currently multiple Markov models in the literature, and we would like to compare these different models. By doing this, we can see what the different models predict for our aneurysm database and use this information to identify the optimal model for our database [3]. We can search for patterns as we evaluate aneurysm growth over time by seeing when the aneurysms would have a high risk of rupture as well as how many aneurysms would be likely to rupture in the long run [3] [4] [11]. Additionally, we can also see if certain variables such as larger aneurysms or rapidly-growing aneurysms increase the likelihood of an early aneurysm rupture as well as increasing the risk of rupture in general over the entire course of the study.

Our findings can be used to determine which aneurysms have a high risk of rupture as well as at what point in time they should be surgically treated. This would help neurosurgeons avoid risky surgical and invasive treatment for aneurysms until it is absolutely necessary [3] [6]-[8] [17].

\section{Objective}

Our study used two Markov models to simulate the natural history of the aneurysms in our current database so that we could measure the amount of growth, rate of growth, and rate of rupture over a 30-year period. We tracked changes over time as well as evaluated the magnitude of the difference in the cumulative rupture probability (CRP) between different categories of the initial aneurysm size, the absolute amount of growth, and the yearly growth rate. Additionally, we determined how high of a risk of rupture there is in certain categories (in the above variables) compared to a baseline risk. We used the Independent T-Test, One-Way between Subjects ANOVA, and Odds Ratio calculation to evaluate all this. Our final analysis proposes the optimal treatment plan for different types of aneurysms.

\section{Method}

\subsection{Demographics}

Our aneurysm database consisted of 290 aneurysms in 206 patients, and the data was collected between 2005 and 2008. The follow-up time for the aneurysms ranged from 2 months to 79 months, with a mean follow-up time of 33 months (SD = 20.76 months).

There were 41 aneurysms in 29 males and 249 aneurysms in 177 females. The age of the patients ranged from 15 to 87 years, with a mean age of $61 \pm 13.2$ years. The initial aneurysm diameter (measured as the maximum diameter) ranged from 1.4 to $34.3 \mathrm{~mm}$, with a mean of $4.5 \pm 3.5 \mathrm{~mm}$. When we converted the diameter to volume, the sizes ranged from 1.37 to $20176.8 \mathrm{~mm}^{3}$, with a mean aneurysm volume of $205.6 \pm 1301.8 \mathrm{~mm}^{3}$. The absolute amount of growth ranged from -1.0 to $8.4 \mathrm{~mm}$, with a mean of $0.5 \pm 0.8 \mathrm{~mm}$. The yearly growth rate ranged from $-1.4 \mathrm{~mm} /$ year to $2.7 \mathrm{~mm} /$ year, with a mean of $0.27 \pm 0.46 \mathrm{~mm} /$ year. 


\subsection{Imaging and Statistics}

The original aneurysm data was collected from images via computed tomography angiography. Statistical tests were conducted using Microsoft Excel and SPSS. We used a p-value of 0.05 as the cutoff for statistical significance. For the odds ratios, the result was considered significant if the $95 \%$ confidence interval did not include " 1 ". Because all cases of aneurysm rupture are predictions, we used the expected value of the number of ruptured aneurysms when calculating the odds ratio.

\subsection{Markov Model I}

Markov Model I was originally used by Yoshimoto [16]. We modified the model by removing the equation to predict aneurysm formation because we were interested in what would happen to the current aneurysms in our database. Yoshimoto predicts that the yearly growth rate is related to the aneurysm volume, and the specific formula for volume is as follows:

$$
\text { Aneurysm Volume }=\frac{(\text { Initial Aneurysm Diameter })^{3}}{2} .
$$

This formula is used instead of the traditional volume formula in order to account for the balloon-like shape of the aneurysms [16].

According to Yoshimoto, the mean yearly growth rate is $10 \mathrm{~mm}^{3} /$ year. However, we added a step to account for variation in the growth rates of each aneurysm by assigning $50 \%$ of the aneurysms a growth rate $>10$ $\mathrm{mm}^{3} /$ year and $50 \%$ of the aneurysms a growth rate $<10 \mathrm{~mm}^{3} /$ year. This is similar to using Gaussian probability which was employed by Chang's study [15]. Yoshimoto's sensitivity analysis used $5 \mathrm{~mm}^{3} /$ year and $15 \mathrm{~mm}^{3} /$ year as the lower and upper bounds, respectively. We took these two bounds and marked them as the 2 SD mark from the mean so that $15 \mathrm{~mm}^{3} /$ year was $+2 \mathrm{SD}$ from the mean and $5 \mathrm{~mm}^{3} /$ year was $-2 \mathrm{SD}$ from the mean. Thus the $\mathrm{SD}$ for the yearly growth rate was $2.5 \mathrm{~mm}^{3} /$ year.

In order to determine the specific growth rate for each aneurysm, we first determined which aneurysms were more likely to grow faster. The aneurysms were ranked based on their current yearly growth rate and given a percentile so that the slowest growing aneurysm would be at the $1^{\text {st }}$ percentile while the fastest growing aneurysm would be at the $99^{\text {th }}$ percentile. We then calculated a z-score for each aneurysm (based on the percentile) to see how far above or below the mean growth rate this particular aneurysm's growth rate was at. We transferred this z-score data to the range of growth rates $\left(10 \pm 2.5 \mathrm{~mm}^{3} /\right.$ year $)$ by using the $\mathrm{z}$-score as the SD marker for each aneurysm. Based on the SD marker, we calculated the specific growth rate for each aneurysm. As an example, an aneurysm at the $63^{\text {rd }}$ percentile in monthly growth rate (meaning that it grew faster than $63 \%$ of the other aneurysms) would have a z-score of +0.33 , meaning that it is $+0.33 \mathrm{SD}$ above the mean growth rate. When this z-score is transferred to the range of growth rates $\left(10 \pm 2.5 \mathrm{~mm}^{3} /\right.$ year), this particular aneurysm's growth rate would be $+0.33 \mathrm{SD}$ above the mean growth rate of $10 \mathrm{~mm}^{3} /$ year, and this comes out to be $10.84 \mathrm{~mm}^{3} /$ year.

Yoshimoto calculated the rupture rate to be a function of the aneurysm volume:

$$
\text { Yearly Rupture Rate }=0.002 \times \text { Aneurysm Volume . }
$$

The unit used for aneurysm volume is $\mathrm{mm}^{3}$, and the YRR is expressed as a percentage [16]. We did not make any changes to this portion.

\subsection{Markov Model II}

Markov Model II was originally used by Chang [15]. We used the same formula from Markov Model I to calculate the aneurysm volume. We did not use the formula for growth rate in this study. Instead, for each aneurysm, we used the growth rate that it had displayed since it was originally identified because this was more representative of each aneurysm's true growth behavior. We converted the linear growth rates in our data into cubic growth rates because Markov Model II required a cubic growth rate. We did this by converting the initial and final aneurysm diameters of each aneurysm into volumes, measuring the difference between the initial and final volumes, and dividing the difference by the follow-up time. Some aneurysms had negative growth rates, meaning that these aneurysms would consistently shrink over the 30-year simulation. Because consistent decreases in size are unrealistic, we changed these aneurysms' growth rates to be $0 \mathrm{~mm}^{3} /$ year. 
Chang also calculated the rupture rate as a function of the aneurysm volume:

$$
\text { Yearly Rupture Rate }=1.14 \times 10^{-5} \times \text { Aneurysm Diameter }^{3} .
$$

The unit for diameter is mm, and the YRR is expressed as a decimal [15]. We did not change this portion.

\subsection{Long-Term Simulation}

The long-term simulation occurred over a period that went 30 years into the future. The current aneurysm volumes are recorded as the aneurysm sizes at Year 0. Because none of the aneurysms have ruptured yet, the CRP for Year 0 is $0 \%$. The aneurysm volumes for Year 1 were equal to the volume during Year 0 plus the respective growth rate for each aneurysm. Using the new volumes for Year 1, we calculated the YRR for Year 1 using the formula for rupture rate. The aneurysm volumes for Year 2 would be equal to the volume during Year 1 plus the respective growth rate for each aneurysm, and again, we could calculate the YRR for Year 2 by inserting the new volumes into the formula for rupture rate. This process was repeated for Years 3 through 30 . We ran a separate simulation for each model.

\subsection{Long-Term Cumulative Rupture Probability}

After the 30-year simulation, we had the YRRs for Years 1 through 30. We chose to find the CRP at 5-year intervals, thereby calculating it at Years 5, 10, 15, 20, 25, and 30. To do this, we first derived the probabilities of "No Rupture" for each year from Year 1 through 30 by subtracting the YRR from $100 \%$. Next, for each aneurysm we multiplied the probability of "No Rupture" for Year 1 by the probabilities of "No Rupture" for Years 2 through 5. This gave us the cumulative probability of "No Rupture" at Year 5, and we subtracted this from 100\% to obtain the CRP at Year 5. We repeated this process for the remaining years in order to find the CRP at Years $10,15,20,25$, and 30 .

\subsection{Independent T-Test and One-Way between Subjects ANOVA}

We used the simulation data to compare the long-term changes in the probability of rupture between different categories of aneurysms to see if certain variables were risk factors for rupture. The variables we tested were the initial aneurysm diameter, absolute amount of growth, and yearly growth rate. For the initial aneurysm diameter, we used two methods of categorization: in Method A, the categories were "Less than $4.6 \mathrm{~mm}$ ", "4.6 - $9.4 \mathrm{~mm}$ ", and "9.5 mm or More"; in Method B, the categories were "Less than $3.5 \mathrm{~mm}$ ", "3.5 - $10.5 \mathrm{~mm}$ ", and "10.6 mm or More" [8] [18]. For the absolute amount of growth, the categories were "Significant Growth" and "Non-Significant Growth", and we tried three different cutoffs to differentiate between those two categories: $0.8 \mathrm{~mm}$ growth, $0.9 \mathrm{~mm}$ growth, and $1.0 \mathrm{~mm}$ growth. For the yearly growth rate, we again divided the categories into "Significant Growth" and "No Significant Growth", and we used a cutoff of $0.36 \mathrm{~mm} /$ year to differentiate between the two categories. We compared the differences in the CRP at each 5-year intervals, using the Independent T-Test for the absolute amount of growth and yearly growth rate and the One-Way between Subjects ANOVA for the initial aneurysm diameter. We conducted these tests once for each model.

\subsection{Odds Ratio}

We calculated the odds ratio for the initial aneurysm diameter (using both Method A and Method B of categorization), absolute amount of growth, and yearly growth rate. The odds ratio would let us determine how much more likely certain categories of initial aneurysm diameter or aneurysm growth are to rupture compared to a baseline group of aneurysms. We calculated the odds ratio at each of the 5-year intervals. The baseline categories were the smallest group of initial aneurysm diameters ("Less than $4.6 \mathrm{~mm}$ " for Method A and "Less than 3.5 $\mathrm{mm}$ for Method B") when testing the initial aneurysm diameters and "Non-Significant Growth" when testing the absolute amount of growth and yearly growth rate. We did the odds ratio tests once for each model.

\section{Results}

Our aneurysms grew substantially over the 30-year simulation, and there was a steady increase in the YRR and CRP during that same time period. 


\subsection{Long-Term Changes in Aneurysm Size}

For Markov Model I, the aneurysm volume at Year 0 ranged from 1.4 to $20176.8 \mathrm{~mm}^{3}$ (mean $=205.6 \pm 1301.8$ $\mathrm{mm}^{3}$ ). Additionally, the initial aneurysm size (equal to the maximum diameter) ranged from 1.4 to $34.3 \mathrm{~mm}$ (mean $=4.5 \pm 3.5 \mathrm{~mm}$ ). By Year 30, the aneurysm volume ranged from $115.3 \mathrm{~mm}^{3}$ to $20346.7 \mathrm{~mm}^{3}$, with a mean volume of $506.4 \mathrm{~mm}^{3}\left(\mathrm{SD}=1304.8 \mathrm{~mm}^{3}\right.$ ). The diameter of the aneurysms ranged from 6.1 to $34.4 \mathrm{~mm}$ (mean $=9.2 \pm 2.4 \mathrm{~mm}$ ).

For Markov Model II, the aneurysm volume at Year 0 ranged from 1.4 to $20176.8 \mathrm{~mm}^{3}$ (mean $=205.6 \pm$ $1301.8 \mathrm{~mm}^{3}$ ). Additionally, the initial aneurysm size (equal to the maximum diameter) ranged from 1.4 to 34.3 $\mathrm{mm}$ (mean $=4.5 \pm 3.5 \mathrm{~mm}$ ). By Year 30, the aneurysm volume ranged from $1.4 \mathrm{~mm}^{3}$ to $69314.4 \mathrm{~mm}^{3}$, and the mean volume was $1209.1 \mathrm{~mm}^{3}\left(\mathrm{SD}=6488.4 \mathrm{~mm}^{3}\right)$. The diameter of the aneurysms ranged from 1.4 to $51.8 \mathrm{~mm}$ (mean $=7.8 \pm 6.4 \mathrm{~mm}$ ). Table 1 lists all the data at each 5-year interval. Figure 1 displays the trend in growth over time.

\subsection{Long-Term Changes in Yearly Rupture Rate and Cumulative Rupture Probability}

For Markov Model I, the YRR increased over time due to the increase in the aneurysm volumes, and by Year 30, the mean YRR was $1.0 \%$ (SD $=2.6 \%$ ), ranging from $0.2 \%-40.7 \%$. Similarly, at the end of the 30 year simulation, the CRP ranged from $4.0 \%-100.0 \%$, with a mean of $13.9 \%(\mathrm{SD}=12.9 \%)$.

For Markov Model II, the YRR once again increased in general over time. By Year 30, the mean YRR was 2.3\% $(\mathrm{SD}=10.8 \%)$, and it ranged from $0.0 \%-100.0 \%$. Moreover, the CRP at Year 30 ranged from $0.1 \%-100.0 \%$,

Table 1. This table shows how the aneurysms grew over the course of 30 years, with measurements included from each 5year interval.

\begin{tabular}{|c|c|c|c|c|}
\hline \multicolumn{5}{|c|}{ Markov Model I } \\
\hline & \multicolumn{2}{|c|}{ Aneurysm Volume } & \multicolumn{2}{|c|}{ Aneurysm Diameter } \\
\hline & Range $\left(\mathrm{mm}^{3}\right)$ & Mean $\left(\mathrm{mm}^{3}\right)$ & Range (mm) & Mean (mm) \\
\hline Year 0 & $1.4-20176.8$ & $205.6 \pm 1301.8$ & $1.4-34.3$ & $4.5 \pm 3.5$ \\
\hline Year 5 & 29.9 - 20205.1 & $255.8 \pm 1302.0$ & $3.9-34.3$ & $6.1 \pm 2.9$ \\
\hline Year 10 & $50.4-20233.4$ & $305.9 \pm 1302.3$ & $4.7-34.3$ & $7.0 \pm 2.7$ \\
\hline Year 15 & 66.7 - 20261.7 & $356.0 \pm 1302.8$ & $5.1-34.4$ & $7.7 \pm 2.6$ \\
\hline Year 20 & 82.9 - 20290.1 & $406.2 \pm 1303.3$ & $5.5-34.4$ & $8.3 \pm 2.5$ \\
\hline Year 25 & 99.1 - 20318.4 & $456.3 \pm 1304.0$ & $5.8-34.4$ & $8.8 \pm 2.4$ \\
\hline Year 30 & 115.3 - 20346.7 & $506.4 \pm 1304.8$ & $6.1-34.4$ & $9.2 \pm 2.4$ \\
\hline \multicolumn{5}{|c|}{ Markov Model II } \\
\hline & \multicolumn{2}{|c|}{ Aneurysm Volume } & \multicolumn{2}{|c|}{ Aneurysm Diameter } \\
\hline & Range $\left(\mathrm{mm}^{3}\right)$ & Mean $\left(\mathrm{mm}^{3}\right)$ & Range (mm) & Mean (mm) \\
\hline Year 0 & $1.4-20176.8$ & $205.6 \pm 1301.8$ & $1.4-34.3$ & $4.5 \pm 3.5$ \\
\hline Year 5 & $1.4-20176.8$ & $372.9 \pm 1882.9$ & $1.4-34.3$ & $5.5 \pm 4.2$ \\
\hline Year 10 & $1.4-26061.4$ & $540.1 \pm 2711.0$ & $1.4-37.4$ & $6.2 \pm 4.8$ \\
\hline Year 15 & $1.4-36874.6$ & $707.4 \pm 3620.4$ & $1.4-41.9$ & $6.7 \pm 5.3$ \\
\hline Year 20 & $1.4-47687.9$ & $874.6 \pm 4562.6$ & $1.4-45.7$ & $7.1 \pm 5.8$ \\
\hline Year 25 & $1.4-58501.2$ & $1041.8 \pm 5521.0$ & $1.4-48.9$ & $7.5 \pm 6.1$ \\
\hline Year 30 & $1.4-69314.4$ & $1209.1 \pm 6488.4$ & $1.4-51.8$ & $7.8 \pm 6.4$ \\
\hline
\end{tabular}


with a mean of $14.2 \%(\mathrm{SD}=22.0 \%)$. The complete data is listed in Table 2. Figure 2 displays the trend in CRP over time.

\subsection{Independent T-Test and One-Way between Subjects ANOVA}

When we did the Independent T-Tests and One-Way ANOVAs for Markov Model I, our results show that for the initial aneurysm diameter, there was a statistically significant difference in the CRP using both Method A and Method B. The p-value was less than 0.001 at all of the 5-year intervals (Years 5, 10, 15, 20, 25, and 30). For the absolute amount of growth, we also found a statistically significant difference in the CRP at every 5-year interval except Year 5 when $0.8 \mathrm{~mm}$ was used as the cutoff between "Significant and "Non-Significant" growth. When we used the $0.9 \mathrm{~mm}$ and $1.0 \mathrm{~mm}$ cutoffs, there was a statistically significant difference in the CRP at all 5-year intervals. For the yearly growth rate, there was a statistically significant difference in the CPR between "Significant Growth" aneurysms and "Non-Significant Growth" aneurysms for all of the 5-year intervals except Year 5 (Table 3).

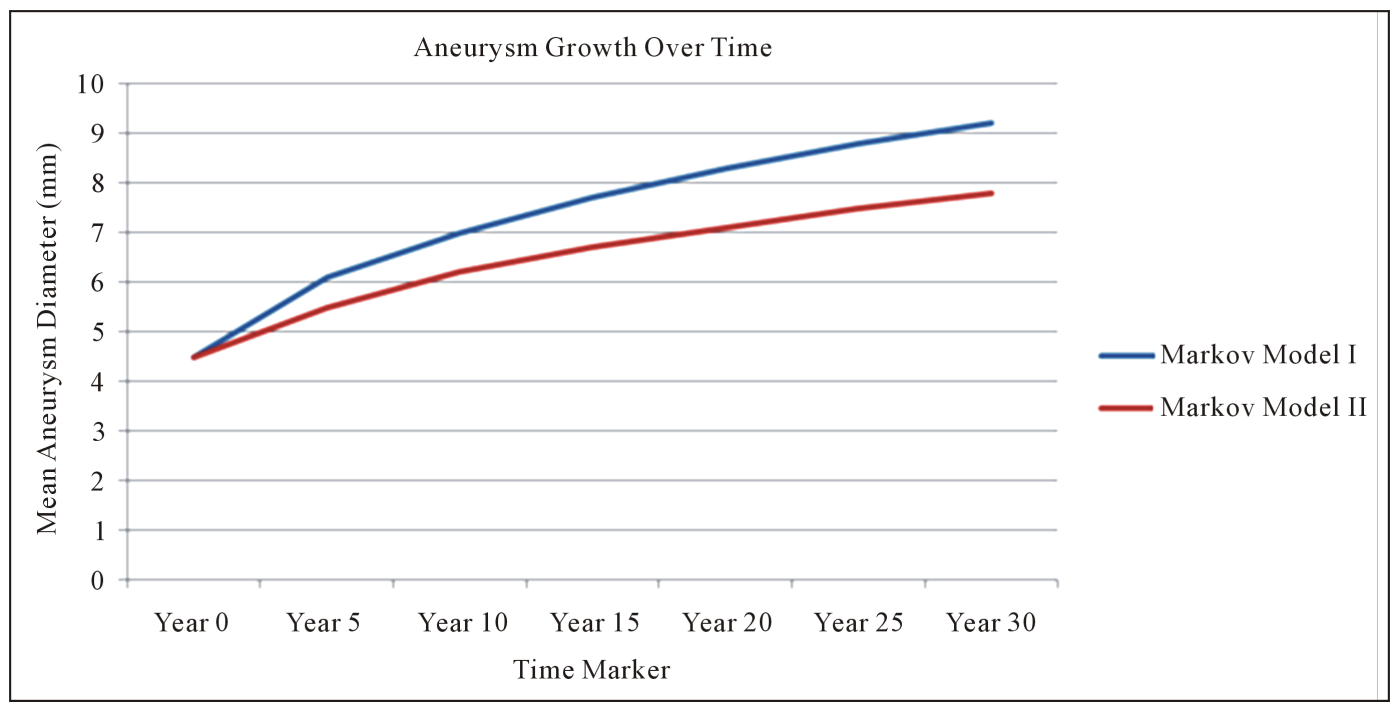

Figure 1. Aneurysm growth over time. The aneurysms gradually grow over 30 years under both models, with a larger mean aneurysm diameter under Markov Model I after 30 years.

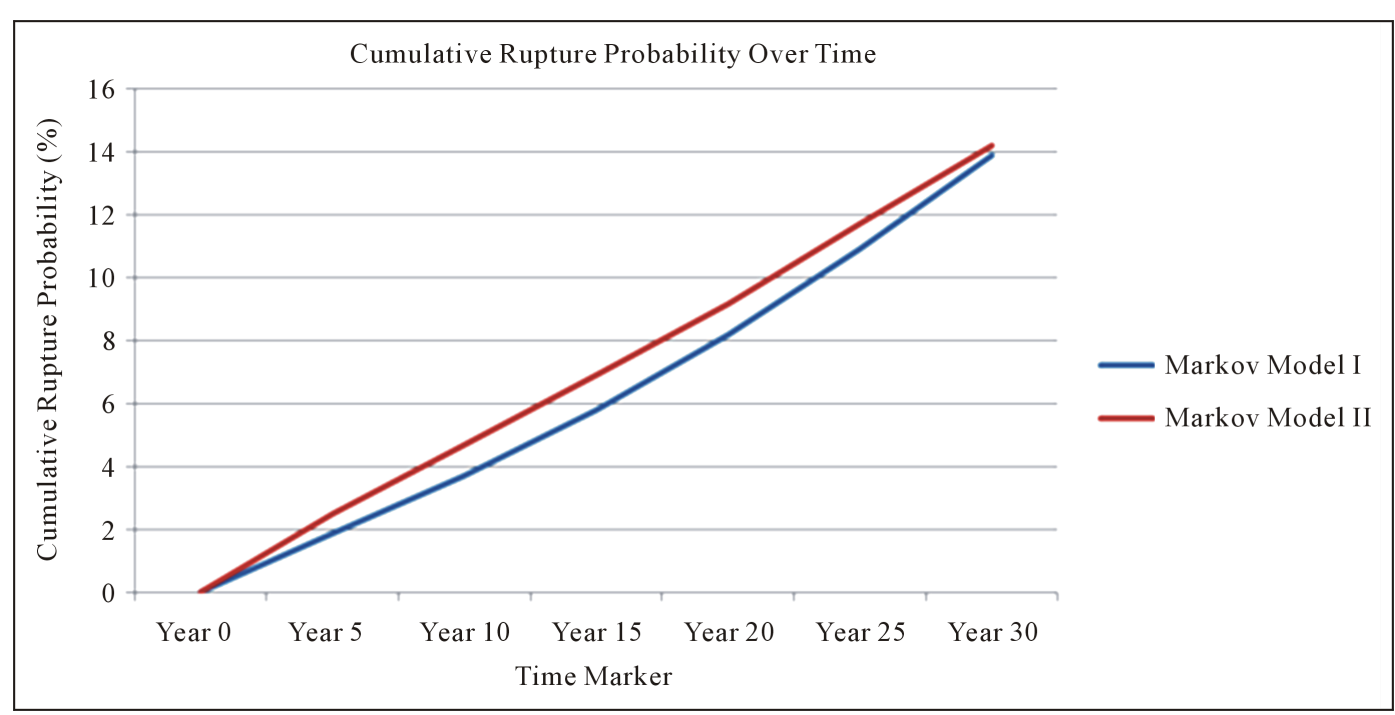

Figure 2. Cumulative rupture probability over time. The cumulative rupture probability steadily increases to the same value under both models. 
Table 2. This table tracks how the yearly rupture rate and cumulative rupture probability increase over time throughout the 30 -year period.

\begin{tabular}{|c|c|c|c|c|}
\hline \multicolumn{5}{|c|}{ Markov Model I } \\
\hline & \multicolumn{2}{|c|}{ Yearly Rupture Rate (YRR) } & \multicolumn{2}{|c|}{ Cumulative Rupture Probability (CRP) } \\
\hline & Range & Mean & Range & Mean \\
\hline Year 5 & $0.1 \%-40.4 \%$ & $0.5 \% \pm 2.6 \%$ & $0.2 \%-92.5 \%$ & $1.9 \% \pm 7.1 \%$ \\
\hline Year 10 & $0.1 \%-40.5 \%$ & $0.6 \% \pm 2.6 \%$ & $0.7 \%-99.4 \%$ & $3.7 \% \pm 9.4 \%$ \\
\hline Year 15 & $0.1 \%-40.5 \%$ & $0.7 \% \pm 2.6 \%$ & $1.3 \%-100.0 \%$ & $5.8 \% \pm 10.9 \%$ \\
\hline Year 20 & $0.2 \%-40.6 \%$ & $0.8 \% \pm 2.6 \%$ & $2.1 \%-100.0 \%$ & $8.2 \% \pm 11.9 \%$ \\
\hline Year 25 & $0.2 \%-40.6 \%$ & $0.9 \% \pm 2.6 \%$ & $3.0 \%-100.0 \%$ & $10.9 \% \pm 12.5 \%$ \\
\hline Year 30 & $0.2 \%-40.7 \%$ & $1.0 \% \pm 2.6 \%$ & $4.0 \%-100.0 \%$ & $13.9 \% \pm 12.9 \%$ \\
\hline \multicolumn{5}{|c|}{ Markov Model II } \\
\hline & \multicolumn{2}{|c|}{ Yearly Rupture Rate (YRR) } & \multicolumn{2}{|c|}{ Cumulative Rupture Probability (CRP) } \\
\hline & Range & Mean & Range & Mean \\
\hline Year 5 & $0.0 \%-46.0 \%$ & $0.9 \% \pm 4.3 \%$ & $0.0 \%-95.4 \%$ & $2.5 \% \pm 9.9 \%$ \\
\hline Year 10 & $0.0 \%-59.4 \%$ & $1.2 \% \pm 6.2 \%$ & $0.0 \%-99.8 \%$ & $4.7 \% \pm 13.4 \%$ \\
\hline Year 15 & $0.0 \%-84.1 \%$ & $1.6 \% \pm 8.3 \%$ & $0.1 \%-100.0 \%$ & $6.9 \% \pm 15.4 \%$ \\
\hline Year 20 & $0.0 \%-100.0 \%$ & $2.0 \% \pm 10.1 \%$ & $0.1 \%-100.0 \%$ & $9.2 \% \pm 17.6 \%$ \\
\hline Year 25 & $0.0 \%-100.0 \%$ & $2.2 \% \pm 10.7 \%$ & $0.1 \%-100.0 \%$ & $11.7 \% \pm 19.8 \%$ \\
\hline Year 30 & $0.0 \%-100.0 \%$ & $2.3 \% \pm 10.8 \%$ & $0.1 \%-100.0 \%$ & $14.2 \% \pm 22.0 \%$ \\
\hline
\end{tabular}

Table 3. This table shows the full list of p-values from the Independent T-Test and One-Way ANOVA when comparing differences in the cumulative rupture probability between different categories of initial aneurysm diameter and aneurysm growth.

\begin{tabular}{rcccccc}
\hline & \multicolumn{3}{c}{ Markov Model I } & & & \\
& Year 5 & Year 10 & Year 15 & Year 20 & Year 25 & Year 30 \\
\hline Initial Aneurysm Diameter (Method A) & $<0.0001$ & $<0.0001$ & $<0.0001$ & $<0.0001$ & $<0.0001$ & $<0.0001$ \\
Initial Aneurysm Diameter (Method B) & $<0.0001$ & $<0.0001$ & $<0.0001$ & $<0.0001$ & $<0.0001$ & $<0.0001$ \\
Absolute Amount of Growth (0.8 mm) & 0.0664 & 0.0337 & 0.0195 & 0.0109 & 0.0056 & 0.0025 \\
Absolute Amount of Growth (0.9 mm) & 0.0485 & 0.0265 & 0.0161 & 0.0095 & 0.0053 & 0.0026 \\
Absolute Amount of Growth (1.0 mm) & 0.0373 & 0.0225 & 0.0146 & 0.0091 & 0.0054 & 0.0029 \\
Yearly Growth Rate & 0.0576 & 0.0215 & 0.0088 & 0.0032 & 0.0009 & 0.0002 \\
\hline & & Markov Model II & & Year & Year 30 \\
\hline Initial Aneurysm Diameter (Method A) & $<0.0001$ & $<0.0001$ & $<0.0001$ & $<0.0001$ & $<0.0001$ & $<0.0001$ \\
Initial Aneurysm Diameter (Method B) & $<0.0001$ & $<0.0001$ & $<0.0001$ & $<0.0001$ & $<0.0001$ & $<0.0001$ \\
Absolute Amount of Growth (0.8 mm) & 0.0222 & 0.0041 & 0.0005 & 0.0001 & $<0.0001$ & $<0.0001$ \\
Absolute Amount of Growth (0.9 mm) & 0.0196 & 0.0042 & 0.0007 & 0.0001 & $<0.0001$ & $<0.0001$ \\
Absolute Amount of Growth (1.0 mm) & 0.0173 & 0.0040 & 0.0007 & 0.0001 & $<0.0001$ & $<0.0001$ \\
Yearly Growth Rate & 0.0106 & 0.0004 & $<0.0001$ & $<0.0001$ & $<0.0001$ & $<0.0001$ \\
\hline
\end{tabular}


When we used Markov Model II, our results show that for the initial aneurysm diameter, there was also a statistically significant difference in the CRP using both Method A and Method B. The p-value was again less than 0.001 at all of the 5-year intervals. For both the absolute amount of growth (for all three cutoffs) and the yearly growth rate, we also found a statistically significant difference in the CRP between "Significant Growth" aneurysms and "Non-Significant Growth" aneurysms for all of the 5-year intervals (Table 3). Figure 3, Figure 4, and Figure 5 display the trends in CRP when we tested for the effects of initial aneurysm diameter, absolute amount of growth, and yearly growth rate, respectively.

\subsection{Odds Ratio for Initial Aneurysm Diameter}

For Markov Model I, there were several significant odds ratios for both Method A and Method B of categorization for initial aneurysm diameter. When we used Method A, we did not find a significant odds ratio for the "4.6 $9.4 \mathrm{~mm}$ ” category at any of the 5-year intervals, but we did find a significant odds ratio at every 5-year interval for the "9.5 mm or More" category. Similarly, when we used Method B, there were no significant odds ratios for the "3.5 - 10.5 mm" category for any of the 5-year intervals, but there was a significant odds ratio at each 5-year interval for the " $10.6 \mathrm{~mm}$ or More" category.

When we tested the absolute amount of growth, there were no significant odds ratios for any 5-year interval when $0.8 \mathrm{~mm}$ and $0.9 \mathrm{~mm}$ were used as the cutoffs between "Significant Growth" and "Non-Significant Growth", but there was a significant odds ratio for every 5-year interval when $1.0 \mathrm{~mm}$ was used as a cutoff. Additionally, there were no significant odds ratios for any 5-year interval when yearly growth rate was tested (Table 4).

For Markov Model II, there were also significant odds ratios for both Method A and Method B. For Method A, there were significant odds ratios at each 5-year interval for the " $9.5 \mathrm{~mm}$ or More" category as well as at every 5-year interval (except Year 5) for the “4.6 - 9.4 mm” category. For Method B, there were significant odds ratios at every 5-year interval for the " $10.6 \mathrm{~mm}$ or More” category, and for the " 3.5 - $10.5 \mathrm{~mm}$ ” category, there were significant odds ratios for Years 15, 20, 25, and 30.

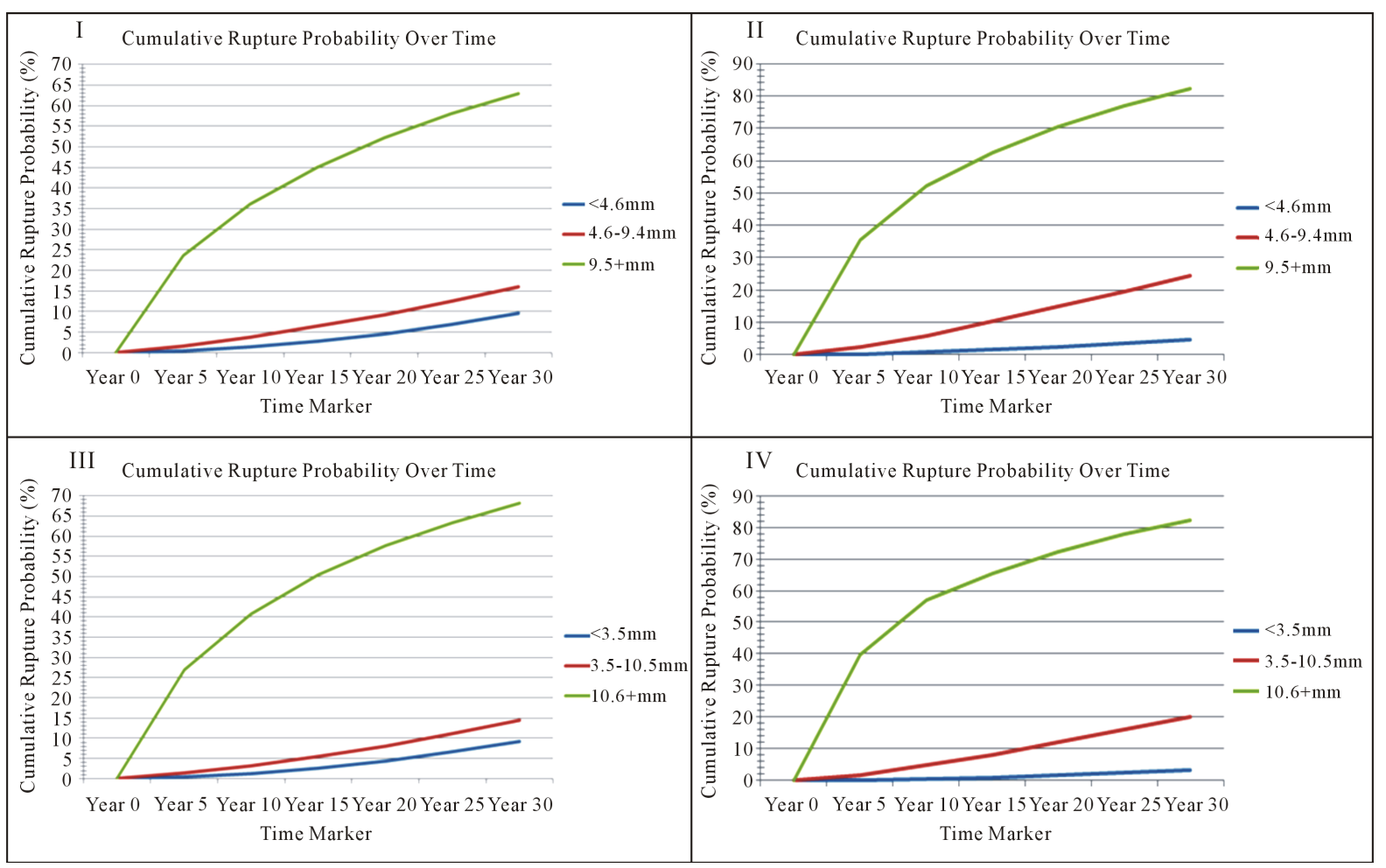

Figure 3. Cumulative rupture probability over time based on initial aneurysm diameter. Figures I and III are for Markov Model I while Figures II and IV are for Markov Model II. As we can see, the large aneurysms have a much higher probability of rupture throughout the 30 -year period while the middle-sized aneurysms have a relatively small likelihood of rupture (though still greater than that of the small aneurysms). 


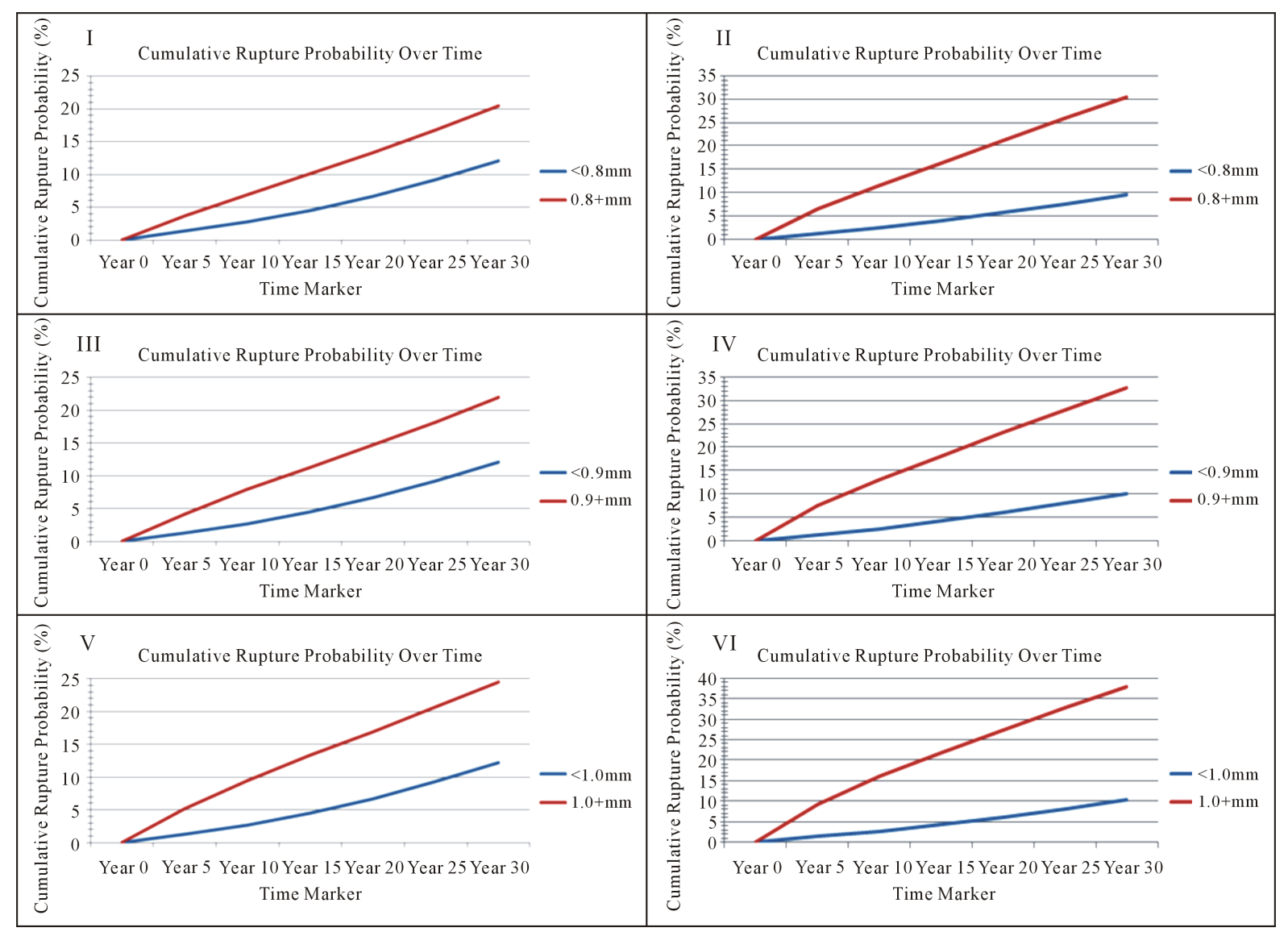

Figure 4. Cumulative rupture probability over time based on absolute amount of growth. Figures I, III, and V are for Markov Model I while Figures II, IV, and VI are for Markov Model II. "Significant Growth" aneurysms clearly have a higher probability of rupture over the long term, and this risk is even greater under Markov Model II.

For both absolute amount of growth (using all three cutoffs to differentiate "Significant Growth" and "NonSignificant Growth") and yearly growth rate, there were significant odds ratios for all of the 5-year intervals (Table 5).

\section{Discussion}

\subsection{Analyzing Long-Term Aneurysm Growth}

The aneurysms steadily grew over the 30-year simulation. With Markov Model I, the smaller aneurysms grew at a faster rate while the larger aneurysms stayed around the same size, consistent with a previous study [13]. Thus, the range for both the aneurysm volume and diameter has become smaller over the course of the simulation, indicating that there is less variation in size. With Markov Model I, the mean diameter steadily increases from 4.5 $\mathrm{mm}$ at Year 0 to $9.2 \mathrm{~mm}$ at Year 30. This is a substantial increase in the mean diameter over the 30 year period, and even the minimum aneurysm diameter is $6.1 \mathrm{~mm}$ after 30 years. Similarly, with Markov Model II, the mean diameter increases steadily from $4.5 \mathrm{~mm}$ at Year 0 to $7.8 \mathrm{~mm}$ at Year 30. However, this increase is not as large as the size change under Markov Model II, and the smallest aneurysms still have a diameter of $1.4 \mathrm{~mm}$. However, the general trends allow us to conclude that even small aneurysms, if left untreated, have a high probability of growing to become fairly large aneurysms, thereby increasing the risk of rupture.

\subsection{Analyzing the Rupture Rate}

The probability of rupture increases each year as the aneurysm grows in size [19]. However, the individual rupture probability never becomes noticeably high until we look at the large aneurysms (initial diameter $>9.5 \mathrm{~mm}$ ). 
Table 4. This table lists the odds ratios for the different categories of initial aneurysm diameter and aneurysm growth when using Markov Model I. The baseline categories were "Less than $4.6 \mathrm{~mm}$ ” for Method A of initial aneurysm diameter; "Less than 3.5 mm” for Method B of initial aneurysm diameter; and "Non-Significant Growth" for the absolute amount of growth and yearly growth rate. The $95 \%$ confidence intervals are included in the parentheses.

\begin{tabular}{|c|c|c|c|c|c|c|}
\hline \multicolumn{7}{|c|}{ Initial Aneurysm Diameter } \\
\hline & Year 5 & Year 10 & Year 15 & Year 20 & Year 25 & Year 30 \\
\hline $\begin{array}{l}\text { Method A } \\
\text { “4.6-9.4 mm” }\end{array}$ & $\begin{array}{c}3.9 \\
(0.26-58.47)\end{array}$ & $\begin{array}{c}2.9 \\
(0.56-14.82)\end{array}$ & $\begin{array}{c}2.4 \\
(0.70-8.10)\end{array}$ & $\begin{array}{c}2.1 \\
(0.78-5.68)\end{array}$ & $\begin{array}{c}1.9 \\
(0.83-4.50)\end{array}$ & $\begin{array}{c}1.8 \\
(0.85-3.81)\end{array}$ \\
\hline $\begin{array}{c}\text { Method A } \\
\text { "9.5 mm or More" }\end{array}$ & $\begin{array}{c}70.8 \\
(5.77-867.83)\end{array}$ & $\begin{array}{c}40.8 \\
(7.71-216.12)\end{array}$ & $\begin{array}{c}28.9 \\
(7.17-116.60)\end{array}$ & $\begin{array}{c}22.5 \\
(6.25-81.09)\end{array}$ & $\begin{array}{c}18.6 \\
(5.40-63.96)\end{array}$ & $\begin{array}{c}16.0 \\
(4.71-54.62)\end{array}$ \\
\hline $\begin{array}{c}\text { Method B } \\
\text { “3.5 - } 10.5 \text { mm” }\end{array}$ & $\begin{array}{c}3.6 \\
(0.18-71.39)\end{array}$ & $\begin{array}{c}2.6 \\
(0.45-14.84)\end{array}$ & $\begin{array}{c}2.1 \\
(0.61-7.59)\end{array}$ & $\begin{array}{c}1.9 \\
(0.70-5.20)\end{array}$ & $\begin{array}{c}1.8 \\
(0.75-4.07)\end{array}$ & $\begin{array}{c}1.6 \\
(0.78-3.44)\end{array}$ \\
\hline $\begin{array}{c}\text { Method B } \\
\text { “10.6 mm or More” }\end{array}$ & $\begin{array}{c}94.7 \\
(5.00-1796.64) \\
\end{array}$ & $\begin{array}{c}53.7 \\
(8.08-356.48) \\
\end{array}$ & $\begin{array}{c}37.7 \\
(7.91-180.17) \\
\end{array}$ & $\begin{array}{c}29.4 \\
(6.99-123.30)\end{array}$ & $\begin{array}{c}24.3 \\
(6.04-97.44)\end{array}$ & $\begin{array}{c}20.9 \\
(5.21-83.51)\end{array}$ \\
\hline \multicolumn{7}{|c|}{ Absolute Amount of Growth } \\
\hline & Year 5 & Year 10 & Year 15 & Year 20 & Year 25 & Year 30 \\
\hline $0.8 \mathrm{~mm}$ Cutoff & $2.8(0.49-15.67)$ & $2.6(0.75-9.24)$ & $2.4(0.84-6.63)$ & $2.2(0.88-5.24)$ & $2.0(0.90-4.42)$ & $1.9(0.90$ - 3.89) \\
\hline $0.9 \mathrm{~mm}$ Cutoff & $3.3(0.58-18.74)$ & $3.0(0.85-10.83)$ & $2.7(0.94-7.67)$ & $2.4(0.96-5.99)$ & $2.2(0.96-4.99)$ & $2.0(0.96-4.36)$ \\
\hline $1.0 \mathrm{~mm}$ Cutoff & $4.1(0.71-23.94)$ & $3.7(1.02-13.68)$ & $3.2(1.09-9.54)$ & $2.8(1.09-7.37)$ & $2.6(1.07-6.08)$ & $2.3(1.05-5.25)$ \\
\hline \multicolumn{7}{|c|}{ Yearly Growth Rate } \\
\hline & Year 5 & Year 10 & Year 15 & Year 20 & Year 25 & Year 30 \\
\hline $0.36 \mathrm{~mm} /$ year Cutoff & $2.7(0.48-15.01)$ & $2.6(0.76-9.07)$ & $2.4(0.88-6.65)$ & $2.2(0.94-5.33)$ & $2.1(0.97-4.55)$ & $2.0(0.99-4.06)$ \\
\hline
\end{tabular}

Table 5. This table lists the odds ratios for the different categories of initial aneurysm diameter and aneurysm growth when using Markov Model II. The baseline categories were "Less than $4.6 \mathrm{~mm}$ ” for Method A of initial aneurysm diameter; "Less than 3.5 mm” for Method B of initial aneurysm diameter; and "Non-Significant Growth" for the absolute amount of growth and yearly growth rate. The $95 \%$ confidence intervals are included in the parentheses.

\begin{tabular}{|c|c|c|c|c|c|c|}
\hline \multicolumn{7}{|c|}{ Initial Aneurysm Diameter } \\
\hline & Year 5 & Year 10 & Year 15 & Year 20 & Year 25 & Year 30 \\
\hline $\begin{array}{c}\text { Method A } \\
\text { "4.6- } 9.4 \mathrm{~mm} "\end{array}$ & $\begin{array}{c}7.8 \\
(0.44-139.17)\end{array}$ & $\begin{array}{c}7.3 \\
(1.22-44.13)\end{array}$ & $\begin{array}{c}7.3 \\
(1.88-28.09)\end{array}$ & $\begin{array}{c}6.9 \\
(2.31-20.41)\end{array}$ & $\begin{array}{c}6.6 \\
(2.60-16.71)\end{array}$ & $\begin{array}{c}6.3 \\
(2.78-14.43)\end{array}$ \\
\hline $\begin{array}{c}\text { Method A } \\
\text { "9.5 mm or More" }\end{array}$ & $\begin{array}{c}172.9 \\
(10.75-2779.91)\end{array}$ & $\begin{array}{c}129.2 \\
(19.34-862.53)\end{array}$ & $\begin{array}{c}106.7 \\
(21.24-535.44)\end{array}$ & $\begin{array}{c}95.5 \\
(21.18-430.15)\end{array}$ & $\begin{array}{c}89.8 \\
(20.03-402.55)\end{array}$ & $\begin{array}{c}91.4 \\
(19.00-439.90)\end{array}$ \\
\hline $\begin{array}{c}\text { Method B } \\
\text { “3.5-10.5 mm” }\end{array}$ & $\begin{array}{c}9.4 \\
(0.21-414.89)\end{array}$ & $\begin{array}{c}8.9 \\
(0.86-92.15)\end{array}$ & $\begin{array}{c}8.6 \\
(1.54-48.05)\end{array}$ & $\begin{array}{c}7.8 \\
(2.02-30.28)\end{array}$ & $\begin{array}{c}7.5 \\
(2.40-23.54)\end{array}$ & $\begin{array}{c}7.1 \\
(2.64-19.27)\end{array}$ \\
\hline $\begin{array}{c}\text { Method B } \\
\text { "10.6 mm or More" }\end{array}$ & $\begin{array}{c}319.3 \\
(7.29-13989.74)\end{array}$ & $\begin{array}{c}239.9 \\
(19.67-2926.51)\end{array}$ & $\begin{array}{c}180.0 \\
(23.57-1374.46)\end{array}$ & $\begin{array}{c}144.2 \\
(23.52-884.58)\end{array}$ & $\begin{array}{c}132.6 \\
(22.91-767.55)\end{array}$ & $\begin{array}{c}127.7 \\
(21.60-755.57)\end{array}$ \\
\hline \multicolumn{7}{|c|}{ Absolute Amount of Growth } \\
\hline & Year 5 & Year 10 & Year 15 & Year 20 & Year 25 & Year 30 \\
\hline $0.8 \mathrm{~mm}$ Cutoff & $4.9(1.10-21.60)$ & $4.8(1.59-14.65)$ & $4.4(1.75-11.21)$ & $4.2(1.87$ - 9.59) & $4.2(1.97-8.74)$ & $4.1(2.06-8.27)$ \\
\hline $0.9 \mathrm{~mm}$ Cutoff & $5.8(1.30-25.64)$ & $5.4(1.77-16.43)$ & $4.9(1.91-12.43)$ & $4.6(2.02-10.64)$ & $4.4(2.07-9.46)$ & $4.3(2.13-8.86)$ \\
\hline $1.0 \mathrm{~mm}$ Cutoff & $7.4(1.64-33.18)$ & $6.8(2.21-21.13)$ & $6.1(2.32-15.80)$ & $5.7(2.40-13.35)$ & $5.4(2.45-11.97)$ & $5.3(2.50-11.25)$ \\
\hline \multicolumn{7}{|c|}{ Yearly Growth Rate } \\
\hline & Year 5 & Year 10 & Year 15 & Year 20 & Year 25 & Year 30 \\
\hline $0.36 \mathrm{~mm} /$ year Cutoff & $5.2(1.15-23.82)$ & $6.0(1.92-18.92)$ & $6.3(2.40-16.29)$ & $6.7(2.87-15.48)$ & $7.0(3.28-15.05)$ & $7.3(3.60-14.82)$ \\
\hline
\end{tabular}


This is consistent with many other studies [7] [9] [10] [15] [16] [20]-[23]. Thus, we can say that aneurysms with a diameter $\leq 9.5 \mathrm{~mm}$ will most likely not rupture, and therefore, the risks of surgical intervention (which range from $10 \%-20 \%$ ) may outweigh the small benefits of preventing what was already an unlikely case of aneurysm rupture [7] [17] [24]. However, the smaller and medium-sized aneurysms may still need to be carefully monitored if significant size changes occur.

The mean CRP seems fairly high for both models. For Markov Model I, the mean CRP steadily increases from 1.9\% at Year 5 to 13.9\% at Year 30, and for Markov Model II, it increases from 2.5\% at Year 5 to $14.2 \%$ at Year 30. However, the CRPs had a positive skew. At Year 30 (under Markov Model I), only 32 aneurysms had a CRP above $20 \%$; only nine aneurysms had a CRP above $40 \%$; and only six aneurysms had a CRP above 50\%. The skew was also present with Markov Model II, although it was smaller. At Year 30, 59 aneurysms had a CRP above 20\%; 31 aneurysms had a CRP above $40 \%$; and 18 aneurysms had a CRP above $60 \%$. These few unusually high CRPs can be attributed to the outliers in aneurysm size in our database (initial diameter $>9.5$ $\mathrm{mm}$ ), and this increases the mean CRP. For Markov Model II, the mean growth rate for the aneurysms was 33 $\mathrm{mm}^{3}$ /year (compared to $10 \mathrm{~mm}^{3} /$ year for Markov Model I), and this may explain the higher distribution of CRPs for Markov Model II. If we only consider the aneurysms with an initial diameter less than or equal to $9.5 \mathrm{~mm}$, the CRP would likely be much lower than $13 \%-14 \%$ at Year 30 under both models.

Additionally, the YRR also had a distribution with a positive skew, with the majority of the YRRs falling below 1\%. With Markov Model I (at Year 30), only 37 aneurysms had a YRR above 1\%, and only five aneurysms had a YRR above 5\%. With Markov Model II, the skew was also present although it was smaller. At Year 30, 41 aneurysms had a YRR above 2\%, and nine aneurysms had a YRR above 10\%. This can again be attributed to the few outliers in aneurysm size.

\subsection{Overall Expected Outcome}

The expected value of ruptured aneurysms represents the most likely outcome for the number of ruptured aneurysms over the course of the simulation. We calculated the expected value at each 5 year mark. By Year 5 (under Markov Model I), we would most likely expect 5 out of the 290 aneurysms to have ruptured, leaving 285 aneurysms unruptured. We would expect 11 total aneurysm ruptures by Year 10; 17 aneurysm ruptures by Year 15; 24 aneurysm ruptures by Year 20; 32 aneurysm ruptures by Year 25; and 40 aneurysm ruptures by Year 30, leaving 250 unruptured aneurysms at the end of the 30-year simulation. Under Markov Model II, we would expect 7 aneurysm ruptures by Year 5; 13 aneurysm ruptures by Year 10; 20 aneurysm ruptures by Year 15; 27 ruptured aneurysms by Year 20; 34 ruptured aneurysms by Year 25; and 41 ruptured aneurysms by Year 30, leaving 249 unruptured aneurysms. Approximately 13\% - 14\% of the aneurysms would rupture over the 30 year period, indicating that the majority of the aneurysms will not rupture in the long term due to the low rupture rate. This is consistent with the literature which states that most aneurysms do not rupture. The aneurysms that are predicted to rupture mainly consist of large and/or fast-growing aneurysms. Thus, instead of risky surgical treatment, regular follow-up visits and imaging results will suffice for all but the largest aneurysms.

\subsection{Analyzing the Independent T-Test and One-Way between Subjects ANOVA Results}

The CRP is significantly different between the different categories of initial aneurysm diameters. This is consistent with previous studies [5] [7] [9] [10] [14]-[16] [18] [20]-[23]. The large categories of initial aneurysm diameter ("9.5 mm or More" and "10.6 mm or More") have a significantly higher CRP compared to the other two categories of initial aneurysm diameters, and the middle-sized categories ("4.6 - 9.4 mm" and "3.5 - 10.5 mm") have a significantly higher CRP compared to the small categories of initial aneurysm diameters ("Less than 4.6 mm" and "Less than $3.5 \mathrm{~mm}$ ") after 10 years (Figure 3). We already expect that the initial aneurysm size affects the CRP based on the models, but our results allow us to quantify the risk of rupture for each group of aneurysms.

The CRP is usually significantly higher for "Significant Growth" aneurysms when compared to "Non-Significant Growth" aneurysms, and this applied to both the absolute amount of growth and the yearly growth rate (Figure 4 and Figure 5). This is again consistent with previous studies, and aneurysm growth should be another factor to consider when deciding on a treatment plan for each aneurysm. We can conclude that aneurysms that have grown quickly in the past are more likely to rupture during the long term due to continued rapid growth [14] [25]. 


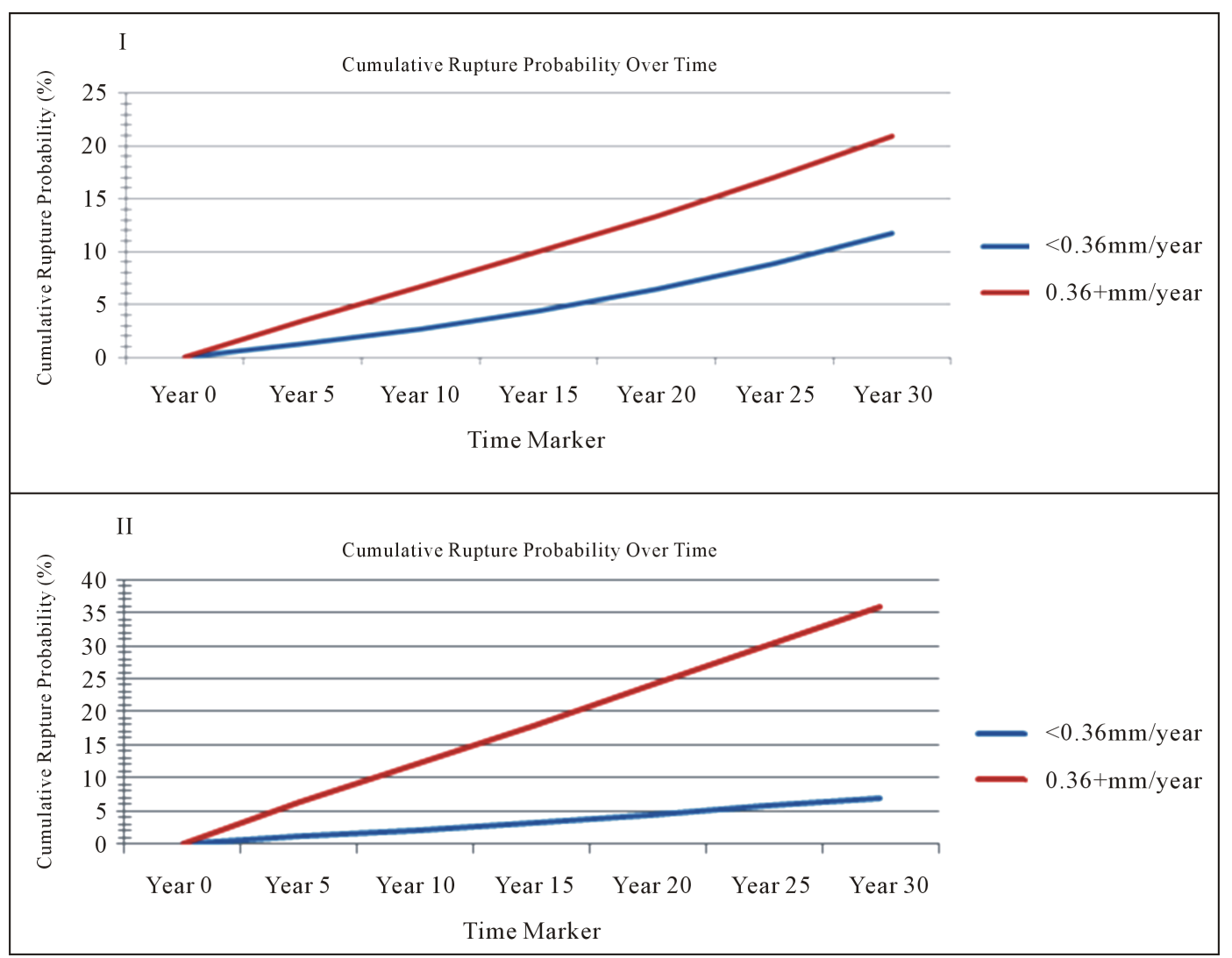

Figure 5. Cumulative rupture probability over time based on yearly growth rate. Figure I is for Markov Model I while Figure II is for Markov Model II. Aneurysms that grow $0.36 \mathrm{~mm} /$ year or faster have a higher probability of rupture, and this difference is greater under Markov Model II.

\subsection{Odds Ratio Analysis}

For the initial aneurysm diameter, the odds ratio was always significant for the largest category of aneurysms. Under Markov Model I, the largest aneurysms were approximately 16 - 21 times more likely to rupture during a 30-year period, and under Markov Model II, they were 90 - 130 times more likely to rupture. The middle group of aneurysms had significant odds ratios starting at Year 15 when Markov Model II was used (they did not have a significant odds ratio at all under Markov Model I), and by Year 30, they were 2 - 4 times more likely to rupture.

For the absolute amount of growth (under Markov Model I), the odds ratio was only significant when using the $1.0 \mathrm{~mm}$ cutoff (starting at Year 10). The "Significant Growth" aneurysms were approximately 2 - 2.5 times more likely to rupture by Year 30 compared to "Non-Significant Growth" aneurysms. For Markov Model II, "Significant Growth" aneurysms were 4.1 - 5.3 times more likely to rupture over 30 years. When we tested the yearly growth rate, there was only a significant odds ratio for Markov Model II, where "Significant Growth" aneurysms were 7.3 times more likely to rupture by Year 30 .

These findings suggest that we definitely need immediate aggressive treatment for large aneurysms $(<9.5 \mathrm{~mm}$ diameter). For medium-sized aneurysms (3.5 - $9.5 \mathrm{~mm}$ diameter), not all aneurysms may need aggressive treatment due to the relatively lower risk, and one way to identify which medium-sized aneurysms need invasive treatment may be to look for significant aneurysm growth (due to the risk identified for "Significant Growth" aneurysms). If the growth rate exceeds $0.36 \mathrm{~mm} /$ year for these medium-sized aneurysms, surgical intervention is recommended.

\subsection{Comparing the Models}

At first look, both models produce very similar results. Markov Model I had a mean CRP of $13.9 \%$ after 30 years while Markov Model II had a similar CRP of 14.2\%. Thus, both models predict similar overall outcomes 
in the long term, and we must look into other factors to evaluate which model is the more optimal model for our aneurysm database.

When examining the distribution of aneurysm size, the range is much smaller for Markov Model I, mostly because we assigned somewhat similar growth rates to the aneurysms. The largest aneurysm diameter after 30 years is $34.4 \mathrm{~mm}$, and this is realistic. With Markov Model II, the largest diameter after 30 years is $51.8 \mathrm{~mm}$, and another two aneurysms have diameters above $45 \mathrm{~mm}$. It is unrealistic to expect even one aneurysm to grow that large, and these unrealistic aneurysm sizes weigh against Markov Model II.

However, the range of sizes for Markov Model I shows that the smallest aneurysm after 30 years is $6.1 \mathrm{~mm}$ in diameter, implying that there are no aneurysms smaller than that. On the other hand, Markov Model II predicts that there will still be several smaller aneurysms after 30 years (as small as $1.4 \mathrm{~mm}$ in diameter). While small aneurysms can grow fast, it is more realistic to expect some aneurysms to remain small instead of saying that all aneurysms will be larger than $6 \mathrm{~mm}$. This weighs in favor of Markov Model II.

The One-Way ANOVAs, Independent T-Tests, and odds ratio tests provide another comparison. For the most part, both models produce low p-values when using the One-Way ANOVA and Independent T-Test in order to compare the differences in CRP between the different categories of aneurysm diameter and growth. However, Markov Model I did not produce a significant p-value for the absolute amount of growth (with a $0.8 \mathrm{~mm}$ cutoff) and yearly growth rate at Year 5, while Markov Model II produced significant p-values for all tests at each 5-year interval. Furthermore, even when comparing the significant p-values, Markov Model II produced lower p-values on average. These results weigh in favor of Markov Model II.

Additionally, the odds ratio tests provided similar results. When Markov Model I was used, there were no significant odds ratios for the middle categories of initial aneurysm diameter, and with aneurysm growth, the only significant odds ratio occurred when we tested the absolute amount of growth with a $1.0 \mathrm{~mm}$ cutoff. In contrast, when we used Markov Model II, we found significant odds ratios at most 5-year intervals for the middle categories of initial aneurysm diameter, and we also found significant odds ratios for all of the tests for aneurysm growth (at every 5-year interval). This ability to more accurately quantify the risk of rupture means that Markov Model II is the better model in this sense.

Lastly, we compare the structure of the two models. The rupture portions of the functions are similar in both models, and the volume is also calculated in the same method for both models. The growth equations are the main difference. Markov Model I has a narrow range of growth values (5 - $15 \mathrm{~mm}^{3} /$ year), which is not the most ideal setup because aneurysms do grow at a wide variety of rates. While Markov Model II has a wider range of growth values, it does assume that some aneurysms will continuously grow at a very fast rate. Although this model takes the aneurysms' previous growth history into account, we cannot realistically expect many aneurysms to keep growing very fast. Thus, neither model has a clear advantage in terms of structure.

After accounting for all this, we conclude that Markov Model I is better. The biggest thing taken into consideration was the aneurysm sizes. Markov Model II produces several very high aneurysm sizes after 30 years, and this reveals a serious flaw with that model. Although Markov Model I does not produce too many small aneurysms after 30 years, this is not as significant a shortcoming as the large aneurysm sizes. Additionally, the higher number of statistically significant results that were produced by Markov Model II can be attributed to the unrealistically large aneurysm sizes under Markov Model II. Thus we believe that Markov Model I is currently the better fit for our aneurysm database.

\subsection{Limitations}

There were a couple limitations for this study. First, the mathematical model that we employed had the same constant for the rupture rate (0.002) for all aneurysms, indicating that the aneurysm volume was the only factor in determining the rupture rate. However, this may not be completely accurate because it is possible for two aneurysms with the exact same volume to have different probabilities of rupture due to other reasons. While we had the option of creating variation for the constant (like we did for the cubic growth rate), we chose not to because we could not find any fair way to assign different rupture constants to each aneurysm. If we can determine a fair method to assign different rupture constants to each aneurysm, we can repeat the simulation and see what occurs.

Our second limitation is that this simulation only provides information on what would happen to our current database of aneurysms. It does not give any general results such as the overall growth rate, rupture rate, or mean 
aneurysm size in the population at large, especially because our database is somewhat unrepresentative due to the very low prevalence of large aneurysms. If we can computerize the simulation, we would then be able to also calculate the full Markov model and its five health states [16].

\subsection{Future Directions}

One future direction is to find a way to assign different rupture constants to each aneurysm when calculating the rupture rate so that we can account for natural differences in the anatomy of each aneurysm. Additionally, another future direction is to come up with our own Markov model and compare it to the existing models to see which model is the best fit.

\section{Conclusion}

In conclusion, aneurysms, if left untreated, can grow a large amount over a long term, and the aneurysms in our database could potentially double in size during a 30-year period. Larger aneurysms and "Significant Growth” aneurysms had a significantly higher CRP. The large aneurysms (initial diameter $>9.5$ mm) should be treated immediately due to a high risk of rupture in the first few years. Medium-sized aneurysms (initial diameter between 3.5 - $9.5 \mathrm{~mm}$ ) have a moderate risk of rupture and should be monitored for significant size increases. Not all aneurysms in this group need invasive treatment, but if the growth rate for any of these aneurysms exceeds $0.36 \mathrm{~mm} /$ year, surgical intervention may be necessary. When comparing the two models, Markov Model I was the optimal model due to the more realistic aneurysm sizes. However, this model should be modified to include more variables, vary the rupture rates of the aneurysms, and increase the range of growth rates.

\section{Acknowledgements}

This work was supported by the Society of Interventional Radiology (SIR) Foundation Dr. Ernest J. Ring Academic Development Grant, The Aneurysm and AVM Foundation (TAAF) Cerebrovascular Research Grant, and a UCLA Radiology Exploratory Research Grant.

\section{References}

[1] Dhar, S., Tremmel, M., Mocco, J., Kim, M., Yamamoto, J., Siddiqui, A.H., et al. (2008) Morphology Parameters for Intracranial Aneurysm Rupture Risk Assessment. Neurosurgery, 63, 185-197. http://dx.doi.org/10.1227/01.NEU.0000316847.64140.81

[2] Hoi, Y., Meng, H., Woodward, S.H., Bendok, B.R., Hanel, R.A., Guterman, L.R., et al. (2004) Effects of Arterial Geometry on Aneurysm Growth: Three-Dimensional Computational Fluid Dynamics Study. Journal of Neurosurgery, 101, 676-681. http://dx.doi.org/10.3171/jns.2004.101.4.0676

[3] Jou, L. and Mawad, M.E. (2009) Growth Rate and Rupture Rate of Unruptured Intracranial Aneurysms: A Population Approach. Biomedical Engineering Online, 8, 1-9. http://dx.doi.org/10.1186/1475-925X-8-11

[4] Juvela, S., Kristiina, P. and Porras, M. (2001) Factors Affecting Formation and Growth of Intracranial Aneurysms: A Long-Term Follow-Up Study. Stroke, 32, 485-491. http://dx.doi.org/10.1161/01.STR.32.2.485

[5] Juvela, S., Porras, M. and Heiskanen, O. (1993) Natural History of Unruptured Intracranial Aneurysms: A Long-Term Follow-Up Study. Journal of Neurosurgery, 79, 174-182. http://dx.doi.org/10.3171/jns.1993.79.2.0174

[6] Kassell, N.F. and Drake, C.G. (1982) Timing of Aneurysm Surgery. Neurosurgery, 10, 514-519. http://dx.doi.org/10.1227/00006123-198204000-00019

[7] Lall, R.R., Eddleman, C.S., Bendok, B.R. and Batjer, H.H. (2009) Unruptured Intracranial Aneurysms and the Assessment of Rupture Risk Based on Anatomical and Morphological Factors: Sifting Through the Sands of Data. Neurosurgical Focus, 26, 1-7. http://dx.doi.org/10.3171/2009.2.FOCUS0921

[8] Matsubara, S., Hadeishi, H., Suzuki, A., Yasui, N. and Nishimura, H. (2004) Incidence and Risk Factors for the Growth of Unruptured Cerebral Aneurysms: Observation Using Serial Computerized Tomography Angiography. Journal of Neurosurgery, 101, 908-914. http://dx.doi.org/10.3171/jns.2004.101.6.0908

[9] Prestigiacomo, C.J., He, W., Catrambone, J., Chung, S., Kasper, L., Pasupuleti, L., et al. (2009) Predicting Aneurysm Rupture Probabilities through the Application of a Computed Tomography Angiography-Derived Binary Logistic Regression Model. Journal of Neurosurgery, 110, 1-6. http://dx.doi.org/10.3171/2008.5.17558

[10] Allcock, J.M. and Canham, P.B. (1976) Angiographic Study of the Growth of Intracranial Aneurysms. Journal of Neurosurgery, 45, 617-621. http://dx.doi.org/10.3171/jns.1976.45.6.0617 
[11] Dell, S. (1982) Asymptomatic Cerebral Aneurysm: Assessment of Its Risk of Rupture. Neurosurgery, 10, 162-166. http://dx.doi.org/10.1227/00006123-198202000-00002

[12] He, W., Hauptman, J., Pasupuleti, L., Setton, A., Farrow, M.G., Kasper, L., et al. (2010) True Posterior Communicating Artery Aneurysms: Are They More Prone to Rupture? A Biomorphometric Analysis. Journal of Neurosurgery, 112, 611-615. http://dx.doi.org/10.3171/2009.8.JNS08731

[13] Chmayssani, M., Rebeiz, J.G., Rebeiz, T.J., Batjer, H.H. and Bendok, B.R. (2011) Relationship of Growth to Aneurysm Rupture in Asymptomatic Aneurysms $\leq 7 \mathrm{~mm}$ : A Systematic Analysis of the Literature. Neurosurgery, 68, 1164-1171.

[14] Koffijberg, H., Buskens, E., Algra, A., Wermer, M.J. and Rinkel, G.J. (2008) Growth Rates of Intracranial Aneurysms: Exploring Constancy. Journal of Neurosurgery, 109, 176-185. http://dx.doi.org/10.3171/JNS/2008/109/8/0176

[15] Chang, H.S. (2006) Simulation of the Natural History of Cerebral Aneurysms Based on Data from the International Study of Unruptured Intracranial Aneurysms. Journal of Neurosurgery, 104, 188-194. http://dx.doi.org/10.3171/jns.2006.104.2.188

[16] Yoshimoto, Y. (2006) A Mathematical Model of the Natural History of Intracranial Aneurysms: Quantification of the Benefit of Prophylactic Treatment. Journal of Neurosurgery, 104, 195-200. http://dx.doi.org/10.3171/jns.2006.104.2.195

[17] Greenburg, I.M. (1984) Cerebral Aneurysm Rupture during Neurosurgery. Neurosurgery, 15, 243-245. http://dx.doi.org/10.1227/00006123-198408000-00016

[18] Weir, B., Disney, L. and Karrison, T. (2002) Sizes of Ruptured and Unruptured Aneurysms in Relation to Their Sites and the Ages of Patients. Journal of Neurosurgery, 96, 64-70. http://dx.doi.org/10.3171/jns.2002.96.1.0064

[19] Qureshi, A.I., Sung, G.Y., Suri, M.F., Straw, R.N., Guterman, L.R. and Hopkins, L.N. (2000) Factors Associated with Aneurysm Size in Patients with Subarachnoid Hemorrhage: Effect of Smoking and Aneurysm Location. Neurosurgery, 46, 44-50. http://dx.doi.org/10.1097/00006123-200001000-00009

[20] Fernandez Zubillaga, A., Guglielmi, G., Vinuela, F. and Duckwiler, G.R. (1994) Endovascular Occlusion of Intracranial Aneurysms with Electrically Detachable Coils: Correlation of Aneurysm Neck Size and Treatment Results. American Journal of Neuroradiology, 15, 815-820.

[21] Hademenos, G.J., Massoud, T.F., Turjman, F. and Sayre, J.W. (1998) Anatomical and Morphological Factors Correlating with Rupture of Intracranial Aneurysms in Patients Referred for Endovascular Treatment. Neuroradiology, 40, 755-760. http://dx.doi.org/10.1007/s002340050679

[22] Rogers, L.A. (1987) Intracranial Aneurysm Size and Potential for Rupture. Journal of Neurosurgery, 67, 475-476.

[23] The International Study of Unruptured Intracranial Aneurysms Investigators (1998) Unruptured Intracranial Aneurysms-Risk of Rupture and Risks of Surgical Intervention. New England Journal of Medicine, 339, 1725-1733. http://dx.doi.org/10.1056/NEJM199812103392401

[24] Batjer, H. and Samson, D. (1986) Intraoperative Aneurysmal Rupture: Incidence, Outcome, and Suggestions for Surgical Management. Neurosurgery, 18, 701-707. http://dx.doi.org/10.1227/00006123-198606000-00004

[25] Miyazawa, N., Akiyama, I. and Yamagata, Z. (2006) Risk Factors for Growth of Unruptured Intracranial Aneurysms: Follow-Up Study by Serial 0.5-T Magnetic Resonance Angiography. Neurosurgery, 58, 1047-1053. http://dx.doi.org/10.1227/01.NEU.0000217366.02567.D2 